\title{
Nanotech thinks big
}

\author{
The science of the incredibly small is shedding its sci-fi image. An \\ anticipated influx of US government funds is nurturing a new wave of \\ interdisciplinary nanoscale research, says Colin Macilwain.
}

$\mathrm{T}$ here is no such thing as bad publicity, it is sometimes said. But ever since Eric Drexler brought the term 'nanotechnology' into vogue in his 1986 book Engines of Creation, some researchers have felt that the field has been burdened by unwanted baggage. Drexler envisioned an era in which factory production lines were replaced by self-replicating, nanoscale 'assemblers' and warned that such entities could supplant humans to become the dominant 'life' forms on our planet. These ideas were quickly seized on by transhumanists - people who imagine what the world will look like after technology has rendered us extinct.

But today, nanotechnology is acquiring the respect researchers in the field believe it deserves. This year, for the first time, the US government has identified nanoscale science and technology as a top research priority. The European Union and other nations are contemplating similar action, and bright young scientists and engineers are starting to gravitate towards the field. "The intellectual drive is even more important than the funds at the moment," says Mihail Roco, nanotechnology programme manager at the US National Science Foundation (NSF), and one of the prime movers in pushing the field up the federal research agenda.

\section{Back to basics}

The US Congress has been asked to fund a new National Nanotechnology Initiative, which would double federal funding for the discipline to $\$ 500$ million in 2001. When President Bill Clinton launched the initiative, his rhetoric might have made some researchers wince - speaking at the California Institute of Technology on 21 January, he boasted of "shrinking the information housed in the Library of Congress into a device the size of a sugar cube". But in reality, the initiative is not built on such grandiose promises. Its core element is a thorough programme of basic research totalling $\$ 170$ million in the 2001 budget request - to investigate the behaviour of materials at scales ranging from 1 to 100 nanometres (a copper atom, for comparison, measures 0.25 nanometres across). This should provide the foundations on which tomorrow's nanotechnology will be built.

Increased effort in basic research is a priority, according to researchers in the field. One of the most exciting areas is the study of

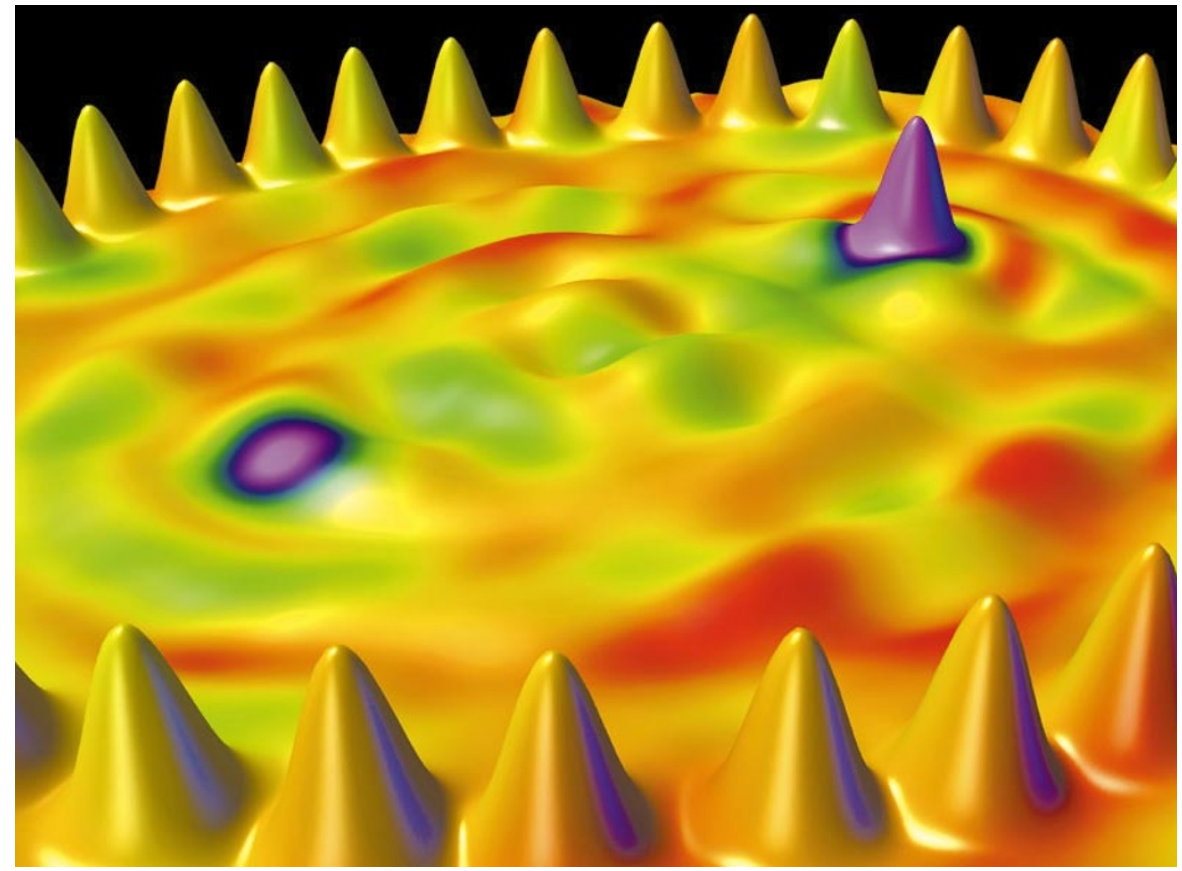

Atomic insight: the scanning tunnelling microscope gives nanoscopic views, such as this quantum well.

carbon nanotubes - sheets of carbon rolled up into tiny, hollow cylinders. These can have alluring semiconducting properties, and so could be used to make nanoscale electronic devices. But the tubes remain awkward to manipulate and are difficult to 'grow' consistently. What is more, exactly how the tubes acquire semiconducting properties is still debated - the property could, for instance, be influenced by some unidentified impurity. Since the discovery of nanotubes, "there's been an explosive growth in papers, but not in understanding", laments Phaedon Avouris, whose team at IBM's Thomas J. Watson research centre at Yorktown Heights, New York, is trying to find some of the answers.

As well as boosting basic research, the new initiative promises to forge links across traditional disciplinary boundaries. Already, solidstate physicists, chemists, engineers and most recently — biologists are uniting into rapidly growing nanoscale research groups at many of the leading US universities. Nanoscience, says Roco, is proving to be "an unexpected meeting point" for scientists from diverse backgrounds. Interdisciplinary collaborations often have to be forced by funding agencies, he says. But in nanoscience, they seem to be forming naturally as researchers from different areas share the same tools.
Nanotechnology gained an early impetus from the invention of what is still an important tool: the scanning tunnelling microscope (STM). In 1982, Gerd Binnig and Heinrich Rohrer at IBM's Zürich Research Laboratory made a discovery that would earn them the 1986 Nobel Prize for Physics. They made electrons 'tunnel' through a narrow gap from a pointed probe to an atomic surface, and showed that the strength of the resulting current is extremely sensitive to the distance between probe and surface. This enables the STM to map surface topography at a resolution of a few tenths of a nanometre. Researchers soon realized that the device could not only image individual atoms, but could also move them around one at a time. In 1991, a team at IBM famously inscribed the company's logo on a nickel surface using 35 atoms of xenon.

\section{Playing atomic marbles}

The STM was joined in 1986 by the atomic force microscope (AFM). This versatile device, also invented by a team led by Binnig, uses a laser to measure the deflection of a cantilevered stylus caused by electrostatic, chemical or magnetic interactions between the tip of the stylus and an atomic surface. It can map the surfaces of solids under gaseous 
or liquid conditions, and can even produce images of biological molecules.

But the ability to observe atomic surfaces and to manipulate a few atoms at a time will not, by itself, lead to technological applications. "It's not about controlling things at the atomic scale — we do that already," explains Tom Theis, head of physical sciences at IBM's Watson centre.

One critical component is self-assembly — the design of molecular building blocks that will automatically link together to form nanostructures. Among the leaders in this area is George Whitesides at Harvard University. Last year, for example, he showed how molecules that self-assemble into a monolayer on a metal substrate can direct the formation of calcite (calcium carbonate) crystals, and can be used to control the density at which arrays of the crystals form ${ }^{1}$. Such fine control over crystal growth is key to the fabrication of useful nanostructures, experts say.

Another important aspect is the integration of the nanoscale with larger structures. For example, Ilhan Aksay at Princeton University in New Jersey, is directing the formation of 'colloidal crystals' at a range of length scales. The colloidal crystals are formed as tiny particles are deposited from suspension in a fluid onto the surface of an electrode. Four years ago, Aksay's team showed that the nanostructure of these crystals can be controlled by adjusting the strength or frequency of the applied electric field ${ }^{2}$. Earlier this year, he showed how the simultaneous use of ultraviolet lithography can organize these crystals at the microscale ${ }^{3}$. "We are making materials with well-defined patterns not only at the nanoscale, but at longer length scales," says Aksay.

Living systems achieve this feat routinely, as Nobel laureate Richard Feynman noted in 1959 in a seminal lecture - called

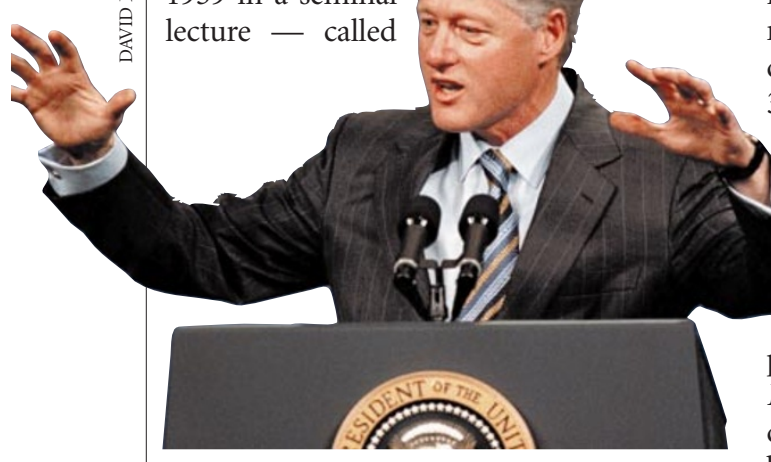

Clinton: backs nanotechnology as a priority.

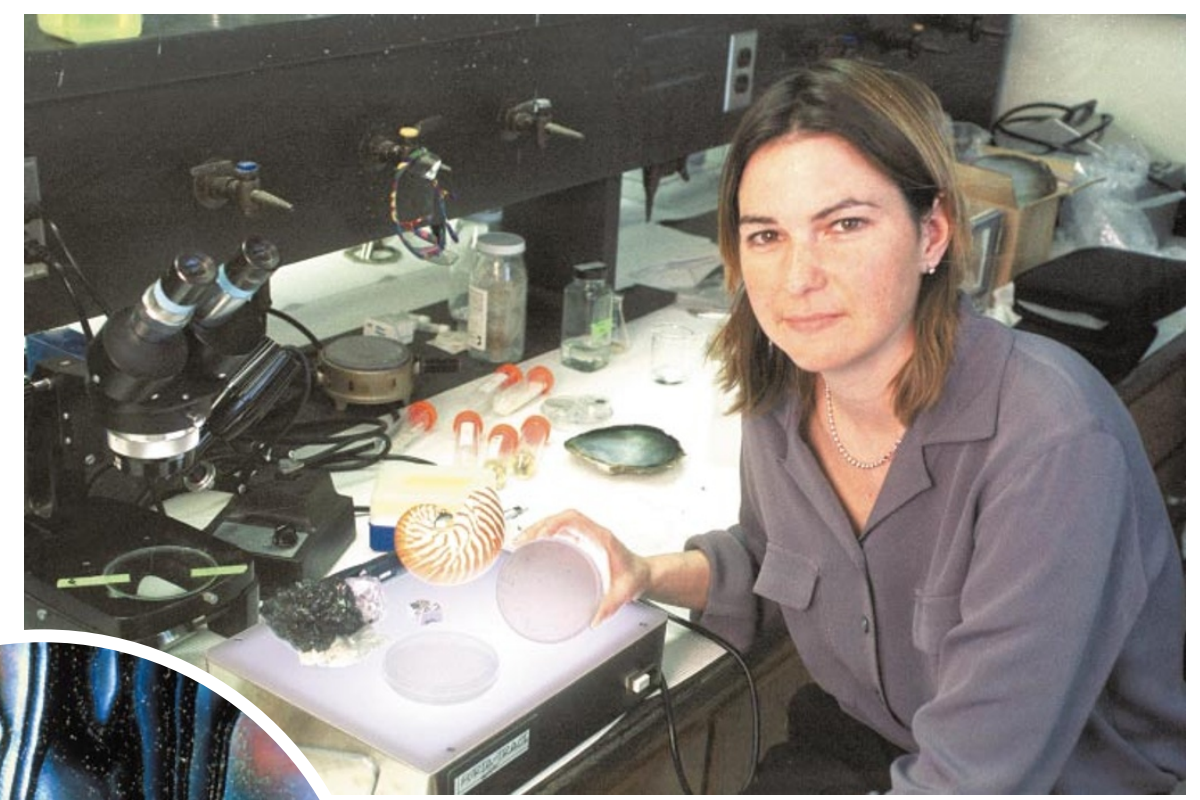

Building blocks: by studying proteins used in the formation of abalone shells (left), Belcher (above) hopes to be able to control crystal growth.

"There is plen- discriminate between, different crystalloty of room at graphic orientations, just like nature does," the bottom" - she says.

that foresaw the development of nanoscience. Living things are built by processes that operate on the tiniest of scales, but which can create structures as large as whales and giant redwoods. Recognizing Feynman's prescience, nanoscientists are increasingly turning to biology for inspiration — although biological systems operate at spatial resolutions a billion or more times higher than the tiniest devices created by nanotechnologists to date. "That gives you an idea of how far we've got to go," says Theis.

\section{Biologists get tooled up}

Yet researchers working at the interface between the physical and life sciences are making rapid progress. Theis cites the "tremendously exciting" work of Angela Belcher of the University of Texas at Austin as an example. Belcher has established how relatively small quantities of proteins determine the structure of crystals of calcium carbonate in abalone shells ${ }^{4}$, making them 3,000 times stronger than the pure mineral. After studying the properties of these proteins with $\mathrm{AFMs}^{5}$, her team has now gone on to identify proteins that bind in a similar way with semiconducting materials such as gallium arsenide and silicon - and published these findings in last week's Nature ${ }^{6}$. Such proteins, Belcher believes, could one day be used to direct the assembly of nanoscale electronic devices. "We are finding things that can bind with, and can
At IBM's Zürich centre, meanwhile, researchers led by Jim Gimzewski have constructed arrays of tiny, gold-plated silicon cantilevers. They hope that these structures will allow them to develop a new generation of chips that use nanomechanics, rather than radioactive or fluorescent tagging, to analyse DNA and other biomolecules. Already, the team has applied DNA bases to the tips of the cantilevers and shown that a simple array can distinguish between genetic sequences that differ by just one base?

One problem with nanoscale biology is that biological samples are hard to manipulate - living cells tend to stick stubbornly to typical substrates such as silicon. But following the lead of Whitesides, who in the 1980s pioneered the use of ultraviolet lithography to cut moulds from silicon and so make tiny silicone-rubber components, researchers now use nanoengineered silicon templates to make components out of more bio-friendly materials. Today, they use electron-beam lithography to cut the moulds with even greater precision.

For example, Bob Austin, a Princeton biophysicist, is working to produce a 'lab-ona-chip' that will manipulate and process living cells, extracting their DNA for analysis. Building on earlier work, in which his team showed that simple urethane-coated microarrays could be used to sort white blood cells into their various classes ${ }^{8}$, Austin is now working with layers of silicone rubber, to fashion structures that ultimately will include tiny valves and pumps. In essence, Austin aims to build a microscopic process plant. At this scale, working with fluids is very different from dealing with bulk flows, 
as the motion of the liquids is governed by the rules of capillary flow.

Nanoscience has also begun to attract the attention of the US National Institutes of Health, which will host a nanotechnology and biomedicine conference on 25-26 June. Last month, its National Cancer Institute (NCI) in Bethesda, Maryland, signed an agreement with the space agency NASA to study the medical potential of nanoparticles. Unlike particles in conventional powders, these nanoparticles have precisely defined and uniform dimensions. Such particles could be useful for drug delivery within the body. At present, administering drugs that do not dissolve in water is difficult. But nanoparticles could carry these molecules around the body, suspended in the blood.

Nanoparticles might also be used in diagnosis, bearing molecules that will bind to specific targets through the bloodstream for instance, molecules on the surface of particular types of cancer cell. NASA will help the NCI with remote-sensing technologies to monitor the behaviour of such nanoparticles in the body.

\section{Battling for nanoscopic mastery}

Given this upsurge in interest, and the lure of funding from the nanotechnology initiative, universities across the United States are racing to stake their claims in nanoscale science. Stanford University in California and Cornell University in Ithaca, New York, are the two main 'nodes' in the existing network of nanotechnology centres established by the NSF. Both house major nanofabrication facilities, with clean rooms containing millions-of-dollars-worth of equipment outside of industrial laboratories, only Delft University of Technology in the Netherlands boasts such an impressive range.

But Stanford and Cornell are about to get some competition. Earlier this year, Northwestern University in Evanston, Illinois, announced plans to spend $\$ 30$ million on a nanofabrication facility of its own. Harvard intends to make a similar investment on a new Center for Imaging and Mesoscale Structures - 'mesoscale' being a term longused by physicists to refer to structures with dimensions measured in micrometres or nanometres.

\section{Web links \\ National Nanotechnology Initiative \\ http://www.nano.gov \\ Engines of Creation \\ http://www.foresight.org/EOC \\ Stanford Nanofabrication Facility \\ http://wwww-snf.stanford.edu \\ Cornell Nanofabrication Facility \\ http://www.cnf.cornell.edu}

$\mathrm{NIH}$ conference on nanotechnology and biomedicine

http://www.masimax.com/becon/index.html

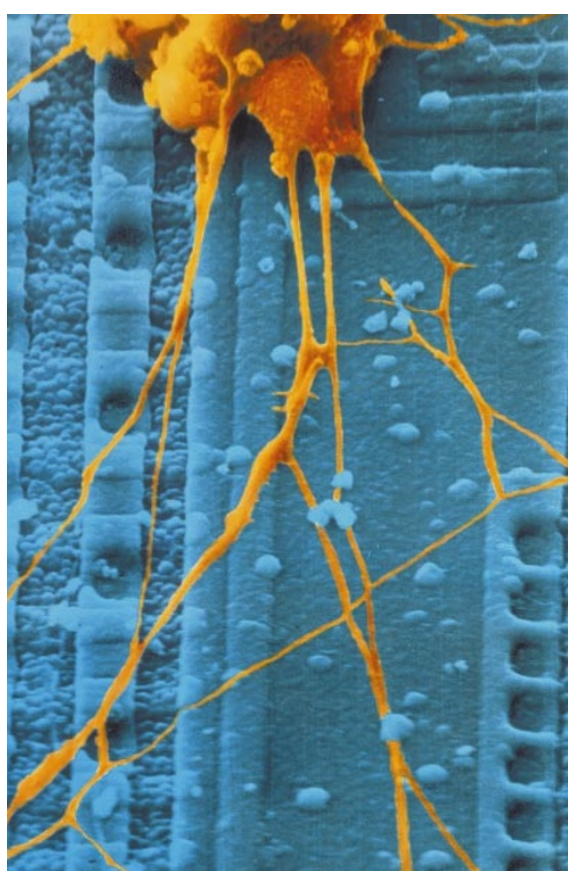

Stuck up: cell samples adhere firmly to silicon, making them hard to handle on the nanoscale.

But the established centres are not sitting still. The Stanford Nanofabrication Facility is housed at the university's Center for Integrated Systems, which was built in 1985 with $\$ 15$ million of backing from 20 industrial sponsors. The facility pioneered the development of RISC (reduced instruction-set computer) silicon microprocessors, used today in many computers, but it is now moving aggressively into interdisciplinary research. "We're committed to opening doors to new academic disciplines," says John Shott, its associate director, who expects "exciting results" in areas ranging from biotechnology to integrated optics. "The electrical engineering department is hiring faculty whose main thrust is to collaborate with people in biomedicine and neuroscience," adds Fabian Pease, a professor in that department.

The Cornell Nanofabrication Facility expects to attract around 450 researchers this year - half of them visiting scientists. "The number of users is increasing by 15 to 20 per cent a year," says Sandip Tiwari, who directs the facility. Cornell plans to spend $\$ 50$ million on a new building for the facility, and has just won a $\$ 20$ million, five-year grant from the NSF to operate a new nanobiotechnology centre. This will be directed by Cornell nanoscientist Harold Craighead, and will make nanoscale tools available to biologists.

Few biologists have woken up to the potential of these tools, says Barbara Baird, a Cornell biophysical chemist who works on the production of biosensors. "But once it is demonstrated in one system there will be a rush from immunologists and everyone else," she predicts.

"The traditional barriers between fields are going away," agrees Richard Siegel, a

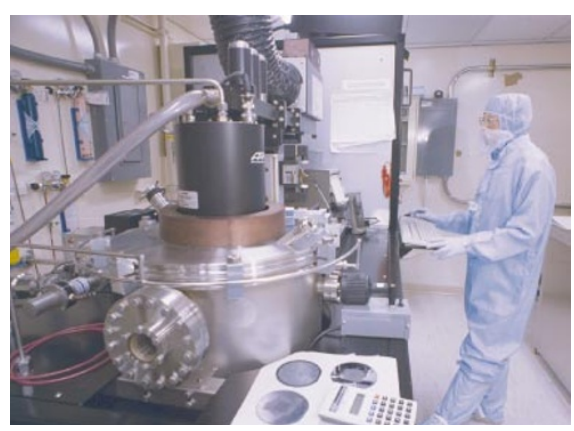

Cutting edge: the plasma etching tool at Cornell is part of the impressive nanotech facility.

pioneer in the use of nanoparticles, who is now head of materials science at Rensselaer Polytechnic Institute in Troy, New York. His department lies in the institute's engineering faculty, but Siegel is now pulling in young scientists from a variety of disciplines.

Inevitably, some are sceptical about this new interdisciplinary dawn. Funding for cross-disciplinary research is always fragile, sceptics note, and the researchers involved can get left out on a limb when projects end. "The biologists are only interested because the physicists are building new tools," says one physicist at Cornell. "If the tools aren't productive, they'll separate again.”

But, at least for now, interdisciplinary nanotechnology has strong support from the NSF, and the prospect of wider backing from the entire US government, whatever happens in this year's presidential election. Although Congress is likely to trim back Clinton's $\$ 500$ million budget request somewhat, politicians of all hues with an interest in science keep stressing the importance of nanotechnology - which indicates that the field's current high profile is not likely to disappear overnight.

Despite this move to the mainstream, the transhumanist connection has not entirely been laid to rest. In the April issue of Wired magazine, for instance, Bill Joy, chief technology officer with Sun Microsystems, went as far as to argue that Drexler had been "naive" in underestimating the dangers posed by nanotechnology. But as the fruits of Clinton's National Nanotechnology Initiative begin to be harvested, its supporters predict that concerns about malevolent nanoassemblers will be replaced by excitement over the field's scientific and economic potential. "We are laying the foundations for the next industrial revolution," declares Theis.

\section{Colin Macilwain is Nature's Senior US Correspondent.}

1. Aizenberg, J., Black, A. J. \& Whitesides, G. M. Nature 398, 495-498 (1999).

2. Trau, M., Saville, D. A. \& Aksay, I. A. Science 272, 706-709 (1996).

3. Hayward, R. C., Saville, D. A. \& Aksay, I. A. Nature 404, 56-59 (2000).

4. Belcher, A. M. et al. Nature 381, 56-58 (1996).

5. Smith, B. L. et al. Nature 399, 761-763 (1999).

6. Whaley, S. R., English, D. S., Hu, E. L., Barbara, P. F. \& Belcher A. M. Nature 405, 665-668 (2000).

7. Fritz, J. et al. Science 288, 316-318 (2000).

8. Carlson, R. H. et al. Phys. Rev. Lett. 79, 2149-2152 (1997). 